INFLAMMATORY BOWEL DISEASE

\title{
Measurement of vitamin D levels in inflammatory bowel disease patients reveals a subset of Crohn's disease patients with elevated 1,25-dihydroxyvitamin D and low bone mineral density
}

\author{
M T Abreu, V Kantorovich, E A Vasiliauskas, U Gruntmanis, R Matuk, K Daigle, S Chen, \\ D Zehnder, Y-C Lin, H Yang, M Hewison, J S Adams
}

Gut 2004;53:1129-1136. doi: 10.1136/gut.2003.036657

See end of article for authors' affiliations

Correspondence to: Dr M T Abreu,

Inflammatory Bowel Disease Center, CedarsSinai Medical Center, 8631 West 3rd St, Suite 245E, Los Angeles, CA 90048, USA;

Maria.Abreu@cshs.org

Revised version received 7 January 2004 Accepted for publication 20 January 2004

\begin{abstract}
Objectives: Many patients with Crohn's disease (CD) have low bone mineral density (BMD) that may not be solely attributable to glucocorticoid use. We hypothesised that low BMD in patients with $C D$ is associated with elevated circulating levels of the active form of vitamin $D, 1,25$-dihydroxyvitamin $D$ $\left(1,25(\mathrm{OH})_{2} \mathrm{D}\right)$. We further hypothesised that this was secondary to increased synthesis of $1,25(\mathrm{OH})_{2} \mathrm{D}$ by inflammatory cells in the intestine. The aim of this study was to examine the relationship between $1,25(\mathrm{OH})_{2} \mathrm{D}$ levels and $\mathrm{BMD}$ in patients with $\mathrm{CD}$.

Methods: An IRB approved retrospective review of medical records from patients with $C D(n=138)$ or ulcerative colitis (UC, $n=29$ ). Measurements of vitamin $D$ metabolites and immunoreactive parathyroid hormone (iPTH) were carried out. BMD results were available for $88 \mathrm{CD}$ and 20 UC patients. Immunohistochemistry or real time reverse transcription-polymerase chain reaction (RT-PCR) for the enzyme $1 \alpha$-hydroxylase was performed on colonic biopsies from patients with CD (14) or UC (12) and normal colons (4).

Results: Inappropriately high levels of serum $1,25(\mathrm{OH})_{2} \mathrm{D}(>60 \mathrm{pg} / \mathrm{ml})$ were observed in $42 \%$ of patients with CD compared with only $7 \%$ in UC, despite no differences in mean iPTH. Serum $1,25(\mathrm{OH})_{2} \mathrm{D}$ levels were higher in $C D(57 \mathrm{pg} / \mathrm{ml})$ versus $U C(41 \mathrm{pg} / \mathrm{ml})(p=0.0001)$. In patients with $C D$, there was a negative correlation between $1,25(\mathrm{OH})_{2} \mathrm{D}$ levels and lumbar $\mathrm{BMD}(r=-0.301, p=0.005)$ independent of therapeutic glucocorticoid use. $1,25(\mathrm{OH})_{2} \mathrm{D}$ levels also correlated with $\mathrm{CD}$ activity. Lastly, immunohistochemistry and RT-PCR demonstrated increased expression of intestinal $1 \alpha$-hydroxylase in patients with CD.

Conclusions: These data demonstrate that elevated $1,25(\mathrm{OH})_{2} \mathrm{D}$ is more common in $\mathrm{CD}$ than previously appreciated and is independently associated with low bone mineral density. The source of the active vitamin D may be the inflamed intestine. Treatment of the underlying inflammation may improve metabolic bone disease in this subgroup of patients.
\end{abstract}

\begin{abstract}
A serious and silent complication of inflammatory bowel disease (IBD) is the development of osteoporosis. ${ }^{1-4}$ Estimates of osteopenia in IBD range from $31 \%$ to $59 \%^{56}$ and osteoporosis from 5\% to $41 \% .{ }^{17-10}$ Some studies have found that osteoporosis is more prevalent in patients with Crohn's disease (CD) than in those with ulcerative colitis (UC). ${ }^{1}{ }^{11-13}$ Other studies however, have found similar degrees of bone loss in CD and UC. ${ }^{14}{ }^{15}$ Lower bone mineral density (BMD) may be present at diagnosis, ${ }^{13}{ }^{16}$ suggesting factors other than medication may contribute to bone loss. The consequences of low BMD in patients with IBD include an increased risk of vertebral or hip fractures and their associated morbidity. ${ }^{17-20}$ Indeed, recent data suggest that the risk of fractures in patients with CD may be underestimated. In a prospective study of $\mathrm{CD}$ patients, asymptomatic fractures were found in $14 \%$ of steroid free patients (including steroid naïve patients) and $15 \%$ of steroid dependent patients. ${ }^{21}$ Similar results were reported by Klaus and colleagues. ${ }^{22}$ These data suggest that the reasons for increased fracture and low BMD in patients with CD are complex.

Because of the prevalence of osteoporosis in patients with $\mathrm{CD}$ and the increased risk of fractures, it is important to identify risk factors resulting in bone loss. Approximately 40$70 \%$ of patients with CD are treated with glucocorticoids and
\end{abstract}

$35 \%$ become dependent on this form of therapy. ${ }^{23} 24$ Glucocorticoid use has generally been accepted as the principal cause of bone loss in these patients although some have not found an association. ${ }^{10}{ }^{14}{ }^{25-31}$ However, in addition to glucocorticoids, other factors are proposed to contribute to accelerated bone loss in patients with $\mathrm{CD}$. These factors include malabsorption of nutrients, ${ }^{32}{ }^{33}$ intestinal resections, ${ }^{34}$ smoking, ${ }^{35}$ inflammatory cytokines, ${ }^{86}$ and vitamin D deficiency. ${ }^{37-40}$ Pre-vitamin D generated in the skin by UVB radiation is converted in the liver to 25-hydroxyvitamin D $(25(\mathrm{OH}) \mathrm{D})$ and subsequently to 1,25-dihydroxyvitamin D $\left(1,25(\mathrm{OH})_{2} \mathrm{D}\right)$ in the renal tubular epithelium. The $1 \alpha$-hydroxylase enzyme mediating the conversion to $1,25(\mathrm{OH})_{2} \mathrm{D}$ is a rate limiting enzyme that is tightly regulated by parathyroid hormone ( $\mathrm{PTH})$ in response to serum calcium. Therefore, deficiency of $25(\mathrm{OH}) \mathrm{D}$ results in hypocalcaemia, increased PTH levels, and a rise in $1,25(\mathrm{OH})_{2} \mathrm{D} .{ }^{41-44}$ The principal action of $1,25(\mathrm{OH})_{2} \mathrm{D}$ is mobilisation of skeletal

Abbreviations: IBD, inflammatory bowel disease; UC, ulcerative colitis; $C D$, Crohn's disease; $B M D$, bone mineral density; $25(\mathrm{OH}) \mathrm{D}$, 25hydroxyvitamin $\mathrm{D} ; 1,25(\mathrm{OH})_{2} \mathrm{D}$, 1,25-dihydroxyvitamin D; PTH, parathyroid hormone; $\mathrm{PTH}$, immunoreactive parathyroid hormone; DXA, dual energy $x$ ray absorptiometry; PCR, polymerase chain reaction; VDR, vitamin $D$ receptor; $\mathrm{mHBS}$, modified Harvey-Bradshaw 
calcium stores through an increase in bone osteoclastic activity. Although vitamin D deficiency can be detrimental, so can inappropriately high levels of the hormonally active $1,25(\mathrm{OH})_{2} \mathrm{D}$. When generation of $1,25(\mathrm{OH})_{2} \mathrm{D}$ is not under the tight regulation of PTH, osteoclast resorption of bone may be accelerated resulting in decreased BMD. While calcium and vitamin D supplementation is recommended for the management of bone loss associated with $\mathrm{IBD}^{45-47}$ not all studies have identified vitamin $\mathrm{D}$ deficiency in these patients ${ }^{25}{ }^{34}$ or a benefit from vitamin D supplementation. ${ }^{48}$

The current study emanates from our observation that CD patients undergoing routine evaluation for metabolic bone disease were frequently found to have increased-not decreased-levels of the active hormonal form of vitamin $\mathrm{D}, 1,25(\mathrm{OH})_{2} \mathrm{D}$. A review of patients' records found that almost half of the CD patients investigated had abnormally elevated levels of $1,25(\mathrm{OH})_{2} \mathrm{D}$ in the absence of hyperparathyroidism. These data are reminiscent of case studies demonstrating increased $1,25(\mathrm{OH})_{2} \mathrm{D}$ in $\mathrm{CD}^{49}$ and sarcoido$\mathrm{sis}^{50}{ }^{51}$ associated with hypercalcaemia and granulomata. CD patients with elevated $1,25(\mathrm{OH})_{2} \mathrm{D}$ in our cohort had lower BMD. Levels of $1,25(\mathrm{OH})_{2} \mathrm{D}$ correlated with CD activity. Our study also demonstrated an increase in expression of the $1 \alpha$-hydroxylase enzyme in the inflamed intestine of CD patients. These novel data suggest that elevated $1,25(\mathrm{OH})_{2} \mathrm{D}$ is another risk factor in the development of low BMD in patients with $C D$ and that the source of its production is the inflamed intestine.

\section{METHODS}

\section{Patient analyses}

The study was approved by the Cedars-Sinai Institutional Review Board and the Scientific Advisory Committee of the General Clinical Research Center for review of patients' medical records. During a nine month period from January 2002 to August 2002, the charts of 167 adult patients attending the Cedars-Sinai Inflammatory Bowel Disease Center were reviewed. As part of the evaluation for metabolic bone disease, patients routinely had evaluation of vitamin D metabolites and immunoreactive parathyroid hormone (iPTH) levels. Charts were examined for history of glucocorticoid use, which was categorised as none, low ( $<6$ months of exposure and/or $<10 \mathrm{mg} /$ day average dose), and high ( $>6$ months of exposure on at least prednisone $10 \mathrm{mg}$ or equivalent) (prednisolone and prednisone are similar with respect to glucocorticoid and mineralocorticoid activity) and results of BMD by dual energy $x$ ray absorptiometry (DXA). Modified Harvey-Bradshaw index was calculated from patients' charts by physicians using data from the clinic visit at the time of the vitamin D draw. ${ }^{52}$ Patient clinical characteristics are shown in table 1 . The group consisted of 138 patients with CD (mean age 37.7 (SEM 1.1) years) and 29 with UC (38.1 (3.3) years). Serum $25(\mathrm{OH}) \mathrm{D}$ and $1,25(\mathrm{OH})_{2} \mathrm{D}$ values were determined by competitive protein binding assay (Esoterix (Endocrine Sciences), Woodland Hills, California, USA). Serum iPTH levels were determined by immunoradiometric assays (Nichols Institute, San Juan Capistrano, California, USA). Calcium, albumin, and creatinine were determined spectrophotometrically. Fractional urinary calcium excretion was measured in a fasting timed two hour collection of urine analysed for calcium and creatinine. Serum biochemistry results in patients with IBD were compared with a cohort of 96 normal subjects (mean age 40.0 (1.0) years) that were matched for age and sex from a database of hormonal values available at Nichols Institute.

$\mathrm{BMD}$ of the lumbar spine and non-dominant proximal femur was assessed in IBD patients by DXA on the same Lunar DPX machine (Lunar Corp., Madison, Wisconsin,
Table 1 Clinical characteristics of inflammatory bowel disease patients

\begin{tabular}{lll}
\hline & CD & UC \\
\hline Sex (M/F) & $75 / 63$ & $17 / 12$ \\
Age at diagnosis $(y)^{*}$ & $25.9(1.3)$ & $28.6(3.8)$ \\
Age at study entry (y)* & $37.7(1.1)$ & $38.1(3.3)$ \\
Postmenopausal & 9 & 3 \\
Glucocorticoid use (none/low/high) & $15 / 18 / 67$ & $5 / 28 / 67$ \\
$\quad(\%)$ & 35 & 0 \\
Small bowel resection (Y/N) & 35 & 0 \\
\hline
\end{tabular}

UC, ulcerative colitis; $C D$, Crohn's disease.

*Values are mean (SEM).

USA); coefficients of variation for measurement of BMD in the spine and femoral neck were $1.0 \%$ and $1.2 \%$, respectively. Areal BMD measurements were compared with a sex matched age matched normative population ("Z" score). Milder bone loss or osteopenia was defined as a BMD of 1.02.49 standard deviations below a control population at peak bone mass, and osteoporosis as BMD $<2.5$ standard deviations below a control population at peak bone mass. ${ }^{53}{ }^{54}$

\section{Immunohistochemistry}

Immunohistochemical analysis of $\alpha$-hydroxylase expression was carried out using an antiserum raised against mouse renal $1 \alpha$-hydroxylase. The antiserum was synthesised using an antigenic region of the reported mouse amino acid sequence (peptide 266-289) which was 70\% homologous to the reported human $1 \alpha$-hydroxylase sequence. The $1 \alpha$-hydroxylase fragment was synthesised as an eight branched multiantigenic peptide and used to immunise a single sheep. An IgG fraction was subsequently prepared from the immune serum (The Binding Site, Birmingham, UK). Preliminary studies using a human proximal tubule cell line (HKC-8) which expresses $1 \alpha$-hydroxylase activity confirmed the specificity of the antiserum for the $56 \mathrm{kDa}$ $1 \alpha$-hydroxylase protein. ${ }^{55}$ Western blot analysis identified a single $1 \alpha$-hydroxylase protein species in these cells, and expression of this was downregulated in the presence of $1,25(\mathrm{OH})_{2} \mathrm{D}$ and upregulated by $\mathrm{PTH}^{55}$ The antiserum was subsequently used to localise $1 \alpha$-hydroxylase in both renal and extrarenal tissues. ${ }^{56} 57$

\section{Real time polymerase chain reaction (PCR) analyses}

Human colonic biopsies were obtained from patients undergoing colonoscopies who consented to having tissue donated for research purposes. This study was reviewed and approved for human subject participation by the Cedars-Sinai Institutional Review Board. Tissue used for this study included mucosal biopsies from patients having screening colonoscopies $(n=4)$ and patients with UC $(n=12)$ or CD $(\mathrm{n}=14)$. Tissue was ground up in RNA Stat-60 with a motorised RNase Free Pellet Pestle (VWR, San Diego, California, USA). Total RNA was isolated using RNA Stat60 according to the manufacturer's protocol. Quantitative real time PCR was conducted for vitamin D receptor (VDR) and $1 \alpha$-hydroxylase using the following TaqMan probes and primers: VDR, forward primer 5'-CTT CAG GCG AAG CAT GAA GC-3', reverse primer 5'-CCT TCA TCA TGC CGA TGT CC-3', probe $5^{\prime}$-AAG GCA CTA TTC ACC TGC CCC TTC AA-3'; $1 \alpha$-hydroxylase, forward primer $5^{\prime}$-CAC CCG ACA CGG AGA CCT T-3', reverse primer 5'-TCA ACA GCG TGG ACA CAA ACA-3', probe 5'-TCC GCG CTG TGG GCT CGG-3'. TaqMan probes and primers for the internal reference gene, $\beta$-actin, were as follows: forward primer $5^{\prime}$-CAT CCT CAC CCT GAA GTA CC-3', reverse primer 5'-GCT CAT TGT AGA AGG TGT GG-3', probe 5'-CAC GGC ATC GTC ACC AAC TG-3'. A total of $1 \mu \mathrm{g}$ of RNA was reverse transcribed using Superscript III 


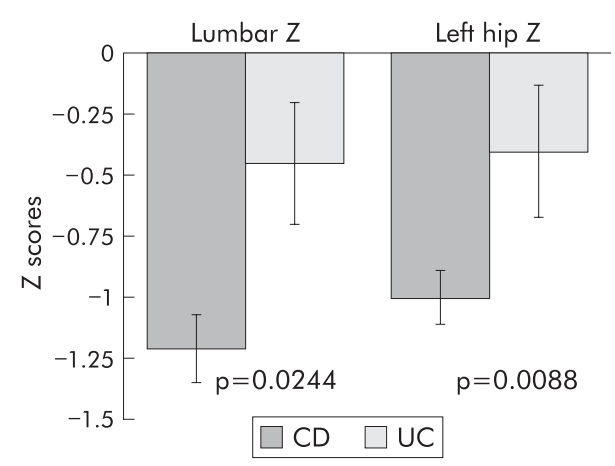

Figure 1 Crohn's disease (CD) patients have lower bone mineral density than ulcerative colitis (UC) patients. Bone mineral density, determined as age matched $Z$ scores, was assessed in patients with $C D$ or UC. Median scores are shown for the lumbar spine ( $n=20$ for UC; $n=96$ for $C D$ ) and the left hip ( $n=18$ for UC; $n=94$ for $C D$ ) with standard error bars. $p$ values show statistically significant differences in $C D$ values compared with equivalent $U C$ analyses.

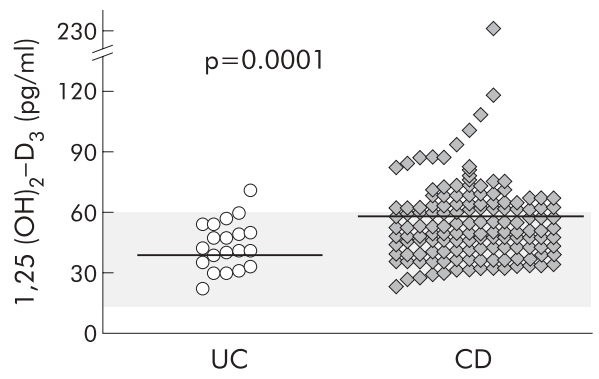

Figure 2 Circulating levels of 1,25-dihydroxyvitamin $D\left(1,25(\mathrm{OH})_{2} \mathrm{D}\right)$ are significantly higher in patients with Crohn's disease (CD) compared with ulcerative colitis (UC). The normal range of $1,25(\mathrm{OH})_{2} \mathrm{D}$ is indicated by the shaded area $(15-60 \mathrm{pg} / \mathrm{ml})$ and mean $1,25(\mathrm{OH})_{2} \mathrm{D}$ levels are indicated by the horizontal lines $(57.77 \mathrm{pg} / \mathrm{ml}$ for CD and $41.3 \mathrm{pg} / \mathrm{ml}$ for UC; $p=0.0001$ ). Overall, $42 \%$ of patients with $C D$ had elevated $1,25(\mathrm{OH})_{2} \mathrm{D}$ compared with only $7 \%$ of UC patients.

(Invitrogen). The following conditions were used: $50^{\circ} \mathrm{C}$ for two minutes, $95^{\circ} \mathrm{C}$ for two minutes, then 50 cycles at $95^{\circ} \mathrm{C}$ for 15 seconds and $60^{\circ} \mathrm{C}$ for one minute. Assays were performed following the predeveloped TaqMan assay reagents protocol (Applied Biosystems, Foster City, California, USA) in an iCycler (Bio-Rad, Hercules, California, USA). The iCycler
Optical System Interface (Bio-Rad) was used to analyse and quantitate samples.

\section{Statistical analysis}

Statistical analysis was performed using SAS computer software (version 6.10; SAS Institute, Inc., Cary, North Caroline, USA, 1994). ${ }^{58}$ Quantitative variables are described as means (SEM) throughout. Non-parametric statistical tests were used to test differences in quantitative variables between the two groups. The Spearman correlation coefficient was used to examine the relationship between vitamin D levels and BMD. Two tailed Pearson correlation analysis was used to examine the correlation between high or low $1,25(\mathrm{OH})_{2} \mathrm{D}$ and PTH. Multivariate analysis was performed to test the association between variables that were significantly associated with low BMD from the univariate analyses.

\section{RESULTS}

\section{Patients with Crohn's disease have lower BMD than patients with ulcerative colitis}

Multiple aetiologies have been suggested for the low BMD associated with CD. BMD results were available for 88 patients with $\mathrm{CD}$ and 20 patients with UC. Age matched Z scores were significantly lower in patients with CD compared with UC (fig 1). Both groups had comparable exposure to glucocorticoids (table 1). Although our small study found lower BMD in CD compared with UC, other population based studies have not found this difference. ${ }^{14}$

\section{Circulating levels of $1,25(\mathrm{OH})_{2} \mathrm{D}$ are elevated in patients with Crohn's disease}

Some studies have reported low $25(\mathrm{OH}) \mathrm{D}$ in patients with $\mathrm{CD}^{39}{ }^{40}$ whereas a case report has described elevated circulating levels of $1,25(\mathrm{OH})_{2} \mathrm{D} .^{49}$ We asked whether patients with $\mathrm{CD}$ had normal circulating levels of the active vitamin D hormone $1,25(\mathrm{OH})_{2} \mathrm{D}$. Compared with patients with UC, mean serum concentration of $1,25(\mathrm{OH})_{2} \mathrm{D}$ was significantly increased in adult patients with CD (table 2, fig 2). Serum $1,25(\mathrm{OH})_{2} \mathrm{D}$ levels were elevated $(>60 \mathrm{pg} / \mathrm{ml})$ in 57 of 138 patients $(42 \%)$ with CD but in only two of 29 patients $(7 \%)$ with UC. Mean $1,25(\mathrm{OH})_{2} \mathrm{D}$ concentration in the $\mathrm{CD}$ group was $57.8(2.5) \mathrm{pg} / \mathrm{ml}$ and differed significantly from the mean value for UC patients $(41.3(2.8)) \quad(\mathrm{p}<0.0001)$. The increase in $1,25(\mathrm{OH})_{2} \mathrm{D}$ could not be explained by serum levels of substrate $25(\mathrm{OH}) \mathrm{D}$ or iPTH, as no patient had low $25(\mathrm{OH}) \mathrm{D}$ with accompanying secondary hyperparathyroidism

Table 2 Circulating vitamin D metabolites and parathyroid hormone balance in adult patients with inflammatory bowel disease

\begin{tabular}{|c|c|c|c|}
\hline & $\begin{array}{l}\mathrm{l}, 25(\mathrm{OH})_{2} \mathrm{D} \\
(\mathrm{pg} / \mathrm{ml})\end{array}$ & $\begin{array}{l}25(\mathrm{OH}) \mathrm{D} \\
(\mathrm{ng} / \mathrm{ml})\end{array}$ & $\begin{array}{l}\text { iPTH } \\
\text { (pg/ml) }\end{array}$ \\
\hline \multicolumn{4}{|l|}{ Normal $(n=96)$} \\
\hline Mean (SEM) & $42.1(1.4)$ & $27.0(0.8)$ & $32.3(0.8)$ \\
\hline Median & 41.5 & 26 & 29 \\
\hline Range & $15-85$ & $5-57$ & $11-74$ \\
\hline \multicolumn{4}{|l|}{$C D(n=138)$} \\
\hline Mean (SEM) & $57.8(2.5)$ & $24.2(1.2)$ & $32.6(2.4)$ \\
\hline Median & 54 & 25.5 & 28.5 \\
\hline Range & $24-233$ & $9-66$ & $10.6-73$ \\
\hline \multicolumn{4}{|l|}{ UC $(n=29)$} \\
\hline Mean (SEM) & $41.3(2.8)$ & $25.9(3.3)$ & $28.8(7.9)$ \\
\hline Median & 42 & 30 & 24.8 \\
\hline Range & $18-72$ & $7-48$ & $10-72$ \\
\hline \multicolumn{4}{|l|}{$t$ test (p values) } \\
\hline Normal $v C D$ & $<0.0001$ & 0.35 & 0.45 \\
\hline Normal $v$ UC & 0.31 & 0.06 & 0.19 \\
\hline$C D \vee \cup C$ & 0.0001 & 0.12 & 0.28 \\
\hline
\end{tabular}


Table 3 Calcium to creatinine excretion in Crohn's disease (CD) patients is elevated compared with the normal population

\begin{tabular}{llllll}
\hline $\mathrm{Ca} /$ creat & $\mathbf{n}$ & Mean & Range & SD & p Value \\
\hline Controls & 96 & 0.066 & $0.01-0.12$ & 0.031 & $<0.001$ \\
$C D$ & 65 & 0.107 & $0.006-0.362$ & 0.07 & \\
\hline
\end{tabular}

(table 2). Indeed there was no correlation between iPTH and $1,25(\mathrm{OH})_{2} \mathrm{D}(r=0.06, \mathrm{p}=0.6)$. We also examined the relationship between iPTH and $1,25(\mathrm{OH})_{2} \mathrm{D}$ in those patients with elevated $1,25(\mathrm{OH})_{2} \mathrm{D}(>60 \mathrm{pg} / \mathrm{ml})$ and again found no correlation $(r=0.184, \mathrm{p}=0.28)$. In the CD cohort, serum $1,25(\mathrm{OH})_{2} \mathrm{D}$ concentration was not correlated with patient sex, duration of disease, cumulative glucocorticoid dose, or history of small bowel resection (data not shown). In our study, the positive predictive value for elevated $1,25(\mathrm{OH})_{2} \mathrm{D}$ in identifying $\mathrm{CD}$ was $97 \%$ whereas the negative predictive value of normal $1,25(\mathrm{OH})_{2} \mathrm{D}$ levels was $75 \%$.

Elevated $1,25(\mathrm{OH})_{2} \mathrm{D}$ levels may result in increased calcium absorption from the intestine, resulting in hypercalcaemia. None of our patients demonstrated hypercalcaemia (mean calcium level 9.3 (SD 0.49)) and there was no correlation between serum calcium and $1,25(\mathrm{OH})_{2} \mathrm{D}$ levels. Serum phosphate levels were not different in control and IBD patients (data not shown). We hypothesised that elevations in serum calcium would be balanced by an increase in urinary calcium excretion. Calcium-creatinine clearance data were available for $65 \mathrm{CD}$ patients. These data were compared with an age and sex matched control group of 96 patients. Our data demonstrated that calcium excretion was significantly higher in CD patients compared with controls (table 3).

We next addressed whether serum levels of $1,25(\mathrm{OH})_{2} \mathrm{D}$ correlated with activity of the underlying CD. Modified Harvey-Bradshaw (mHBS) indices were calculated from patients' clinic visits at the time serum specimens were obtained for vitamin D analysis. In total, mHBS could be calculated for 72 patients in the cohort. There was a significant positive correlation between mHBS and $1,25(\mathrm{OH})_{2} \mathrm{D}$ levels $(r=0.266, \mathrm{p}=0.024)$. When stratified by corticosteroid use at the time of vitamin D sampling, a significant correlation was found between mHBS and $1,25(\mathrm{OH})_{2} \mathrm{D}$ levels in patients taking concurrent corticosteroids $(r=0.68, \mathrm{p}=0.002)$. This correlation did not exist in the absence of concurrent corticosteroid usage $(r=0.106$, $\mathrm{p}=0.473)$. Forty per cent of patients with high $1,25(\mathrm{OH})_{2} \mathrm{D}$

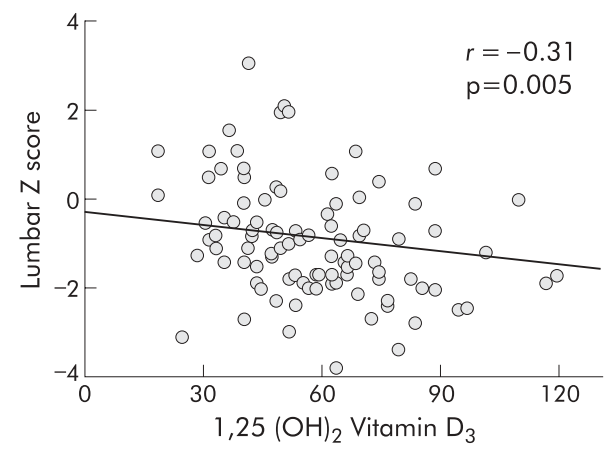

Figure 3 Circulating levels of 1,25-dihydroxyvitamin $\mathrm{D}\left(1,25(\mathrm{OH})_{2} \mathrm{D}\right)$ are inversely correlated with bone mineral density in patients with Crohn's disease. The correlation between lumbar Z scores and $1,25(\mathrm{OH})_{2} \mathrm{D}$ levels is shown. The $r$ value indicates Spearman's correlation coefficient. levels were concurrently taking corticosteroids at the time of vitamin D sampling compared with $34 \%$ of patients with normal $(<60 \mathrm{pg} / \mathrm{ml}) \quad 1,25(\mathrm{OH})_{2}$ D levels $(\mathrm{p}=0.5)$.

\section{$1,25(\mathrm{OH})_{2} \mathrm{D}$ levels are inversely correlated with BMD in Crohn's disease patients}

Although circulating concentrations of vitamin D are important for normal calcium homeostasis and bone metabolism, high levels of the active hormone can result in increased bone resorption with a concomitant decline in $\mathrm{BMD}$. We therefore examined the correlation between BMD ( $\mathrm{Z}$ scores) and $1,25(\mathrm{OH})_{2} \mathrm{D}$ levels in patients with $\mathrm{CD}$. Our data demonstrated a significant negative correlation between $\mathrm{BMD}$ and $1,25(\mathrm{OH})_{2} \mathrm{D}$ levels (table 4, fig 3). This correlation remained in patients in the high glucocorticoid use group (data not shown). Furthermore, multiple regression analysis for risk factors associated with low BMD demonstrated that glucocorticoid use and high $1,25(\mathrm{OH})_{2} \mathrm{D}$ levels were independent risk factors for low BMD (table 5). These data suggest that, in addition to glucocorticoids, high levels of $1,25(\mathrm{OH})_{2} \mathrm{D}$ levels are an important risk factor for the development of osteoporosis in patients with CD.

\section{Intestinal expression of $1 \alpha$-hydroxylase is increased in patients with Crohn's disease}

The enzyme $1 \alpha$-hydroxylase converts $25(\mathrm{OH}) \mathrm{D}$ to active hormonal $1,25(\mathrm{OH})_{2} \mathrm{D}$ and is found predominantly in the kidney. However, other granulomatous diseases such as sarcoidosis are characterised by increased expression and activity of $1 \alpha$-hydroxylase by activated macrophages. ${ }^{50} 5960$ We reasoned that lamina propria mononuclear cells in patients with $\mathrm{CD}$ might express $1 \alpha$-hydroxylase activity. Immunohistochemical analysis of $1 \alpha$-hydroxylase was carried out using colonic biopsies from patients with active and quiescent $\mathrm{CD}$ and compared with renal epithelial cells and a sarcoid granuloma as positive controls. Typical staining shown in fig 4 indicated that the enzyme was present in normal colon but with increased expression in inflamed biopsies from $C D$ patients. Compared with colon from a representative patient with quiescent CD (fig 4C), colon from a patient with active $C D$, complicated by elevated serum $1,25(\mathrm{OH})_{2} \mathrm{D}$ levels, showed intense submucosal staining for $1 \alpha$-hydroxylase in epithelial cells (fig 4D). Increased expression of the enzyme was also demonstrated in macrophages and multinucleated giant cells (fig 4E) similar to that observed in sarcoidosis associated granulomas (fig 4F); the latter disease is the prototypical granuloma forming disease associated with vitamin D mediated hypercalciuria and

Table 4 Circulating levels of 1,25-dihydroxyvitamin D are inversely correlated with bone mineral density (BMD) in patients with Crohn's disease

\begin{tabular}{llll}
\hline BMD site & $\mathbf{n}$ & $\boldsymbol{r}$ & p Value \\
\hline Left hip Z score & 79 & -0.227 & 0.044 \\
Lumbar Z score & 79 & -0.310 & 0.005 \\
\hline
\end{tabular}

Age matched BMD Z scores (lumbar and left hip) for Crohn's disease patients. Sample number $(n)$, correlation coefficient $(r)$, and statistical significance value $(p)$ were determined. 
Table 5 Multiple regression analysis for variables associated with lumbar Z scores in patients with Crohn's disease

\begin{tabular}{lll}
\hline Variable & $\boldsymbol{r}$ & $\mathrm{p}$ Value \\
\hline $1,25(\mathrm{OH})_{2} \mathrm{D}$ & -0.011 & 0.0429 \\
Small bowel resection & -0.049 & 0.8834 \\
Years since diagnosis & -0.007 & 0.6432 \\
\hline $1,25(\mathrm{OH})_{2} \mathrm{D}, 1,25$-dihydroxyvitamin $\mathrm{D} ; \boldsymbol{r}$, correlation coefficient. \\
\hline
\end{tabular}

hypercalcaemia. ${ }^{8}$ In addition to immunohistochemistry, real time PCR of colonic biopsies from patients with CD or UC demonstrated that patients with CD expressed higher levels of $1 \alpha$-hydroxylase whereas both UC and CD patients had reduced expression of VDR compared with normal colonic biopsies (fig 5A, 5B). We conclude from these data that lamina propria mononuclear cells are capable of expressing $1 \alpha$-hydroxylase which, in the presence of the $25(\mathrm{OH}) \mathrm{D}$ substrate, may result in local synthesis of $1,25(\mathrm{OH})_{2} \mathrm{D}$.

\section{DISCUSSION}

Osteoporosis is a well recognised complication of CD and UC. ${ }^{14}{ }^{15}$ What is less clear however are the factors that result in its development and the best approach to its treatment and prevention. ${ }^{17-19}{ }^{61-63}$ Based on our findings, we suggest that elevated $1,25(\mathrm{OH})_{2} \mathrm{D}$ is an additional risk factor predisposing to development of osteoporosis in a subset of CD patients.

Our finding of normal $25(\mathrm{OH}) \mathrm{D}$ and elevated $1,25(\mathrm{OH})_{2} \mathrm{D}$ is in contrast with previous studies demonstrating low $25(\mathrm{OH}) \mathrm{D}$ and secondary hyperparathyroidism in patients with CD. ${ }^{39}{ }^{40}$ Some have suggested vitamin D supplementation in patients with CD to prevent bone $\operatorname{loss}{ }^{47}$ whereas others have found normal $25(\mathrm{OH}) \mathrm{D}$ and serum calcium levels in $\mathrm{CD}^{64}$ The reasons for the divergent results may be geographic location (Southern California versus northern climates) and limited intestinal resections in recently ascertained patient cohorts. Patients with extensive surgical resections for CD were commonplace at the time most of the previous vitamin D studies were performed ${ }^{33} 37$ and may have had reduced absorption of cholecalciferol and $25(\mathrm{OH}) \mathrm{D} .{ }^{65}$ The change in treatment of $\mathrm{CD}$ away from surgery and, to some extent, away from systemic glucocorticoids, requires a revisiting of established tenets with respect to vitamin D.

Our study demonstrated an inverse correlation between $1,25(\mathrm{OH})_{2} \mathrm{D}$ levels and BMD. Although we demonstrated this correlation, it is not possible to demonstrate causality between the two. We believe that the increase in systemic $1,25(\mathrm{OH})_{2} \mathrm{D}$ is the result of the underlying inflammation in CD. Consistent with this notion, disease activity correlated with $1,25(\mathrm{OH})_{2} \mathrm{D}$ levels, and biopsies from patients with active $\mathrm{CD}$ and elevated $1,25(\mathrm{OH})_{2} \mathrm{D}$ demonstrated increased expression of $1 \alpha$-hydroxylase required for conversion of $25(\mathrm{OH}) \mathrm{D}$ to its active $1,25(\mathrm{OH})_{2} \mathrm{D}$ form. Elevated $1,25(\mathrm{OH})_{2} \mathrm{D}$ may therefore be a direct cause of bone loss or a surrogate marker for the type of intestinal inflammation resulting in osteoporosis. Because of the retrospective nature of our study, it is not possible to determine whether the increase in $1,25(\mathrm{OH})_{2} \mathrm{D}$ predates the onset of osteoporosis or is related to the severity of the underlying $\mathrm{CD}$. Multivariate analyses demonstrated that $1,25(\mathrm{OH})_{2} \mathrm{D}$ is an independent risk factor for low BMD but the use of corticosteroids was high in this patient population. Nevertheless, our findings help to identify a subgroup of patients with an additional risk factor for osteoporosis and one that can be used to make decisions on further evaluation and therapy.

We have shown previously that intestinal epithelial cells normally express $1 \alpha$-hydroxylase. ${ }^{56}$ The present study shows for the first time that lamina propria mononuclear cells also
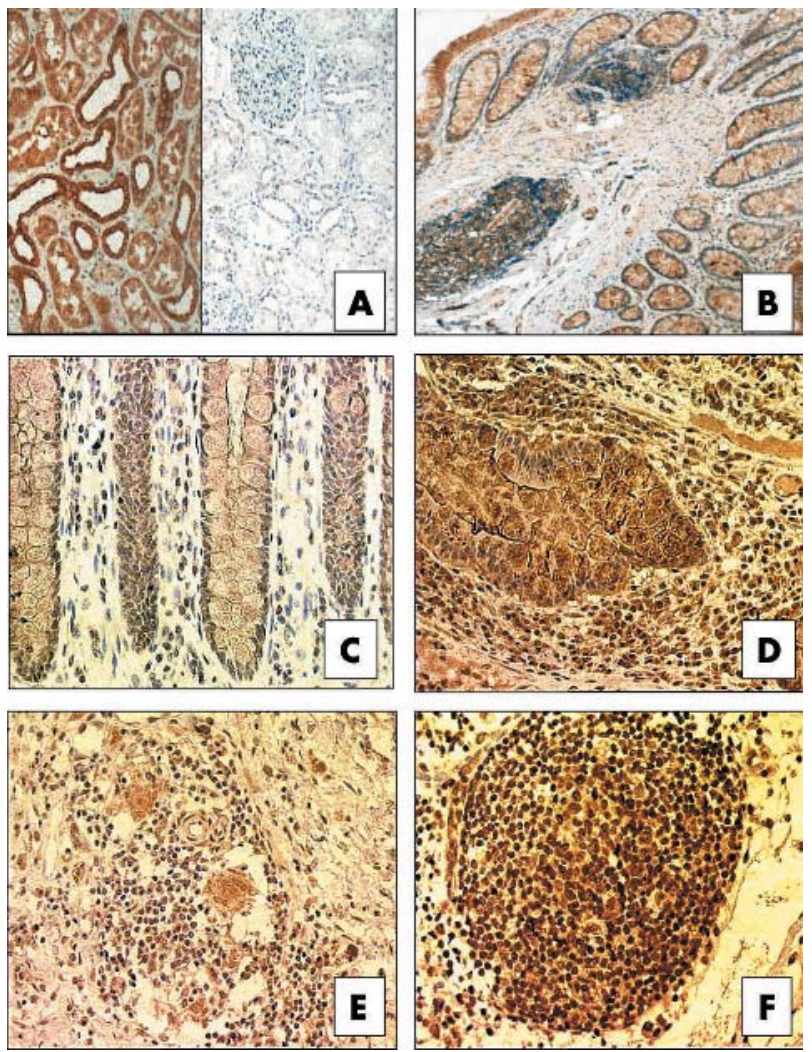

Figure 4 Expression of $1 \alpha$-hydroxylase in normal colon and Crohn's disease. (A) Positive control demonstrating characteristic anti-

$1 \alpha$-hydroxylase staining in human renal tubular epithelial cells (left, $250 \times$ magnification). Non-specificity control of human kidney stained with antiserum preincubated with immunising peptide (right, $250 \times$ magnification). (B-D) Immunostaining for $1 \alpha$-hydroxylase in colon from a normal subject (B) and subjects with quiescent (C) and active Crohn's disease (D), respectively (350 × magnification). ( $E, F)$ Comparison of immunostaining of $1 \alpha$-hydroxylase in granulomas from the colon of a patient with Crohn's disease and elevated serum 1,25-dihydroxyvitamin $D(E)$ and the skin of a patient with active sarcoidosis (F) (350x magnification).

express $1 \alpha$-hydroxylase and therefore have the ability to generate $1,25(\mathrm{OH})_{2} \mathrm{D}$ locally. Furthermore, in the presence of intestinal inflammation, the increased number of lamina propria mononuclear cells combined with the availability of $25(\mathrm{OH}) \mathrm{D}$ as the substrate for $1 \alpha$-hydroxylase results in the generation of higher levels of $1,25(\mathrm{OH})_{2} \mathrm{D}$. We propose a model in which excess $1,25(\mathrm{OH})_{2} \mathrm{D}$ from the inflamed gut spills over into the circulation and may have the unintended effect of contributing to metabolic bone disease in patients with CD (fig 6). This situation is similar to that seen in other granulomatous diseases such as sarcoidosis ${ }^{51}$ in which mature macrophages express $1 \alpha$-hydroxylase resulting in hypercalcaemia and hypercalciuria. ${ }^{50} 5960$ In both sarcoidosis and $\mathrm{CD}$, the most likely function of extrarenal $1,25(\mathrm{OH})_{2} \mathrm{D}$ production is as an endogenous feedback response to inflammation. A variety of studies have documented the immunosuppressive properties of $1,25(\mathrm{OH})_{2} \mathrm{D}$, stimulating interest in the potential use of synthetic analogues of vitamin $\mathrm{D}$ as therapy for autoimmune disease and transplantation rejection. ${ }^{66-68}$ However, recent data from our group suggest that vitamin D may also fulfil a protective role, with macrophages, dendritic cells, and epithelial cells being potential sources of immunomodulatory $1,25(\mathrm{OH})_{2} \mathrm{D} .{ }^{6970}$. $\mathrm{CD}$ is characterised by Thl mediated intestinal inflammation with a subset of patients demonstrating microgranuloma. ${ }^{71} 72$ Thus the goal of local $1,25(\mathrm{OH})_{2} \mathrm{D}$ production may be 

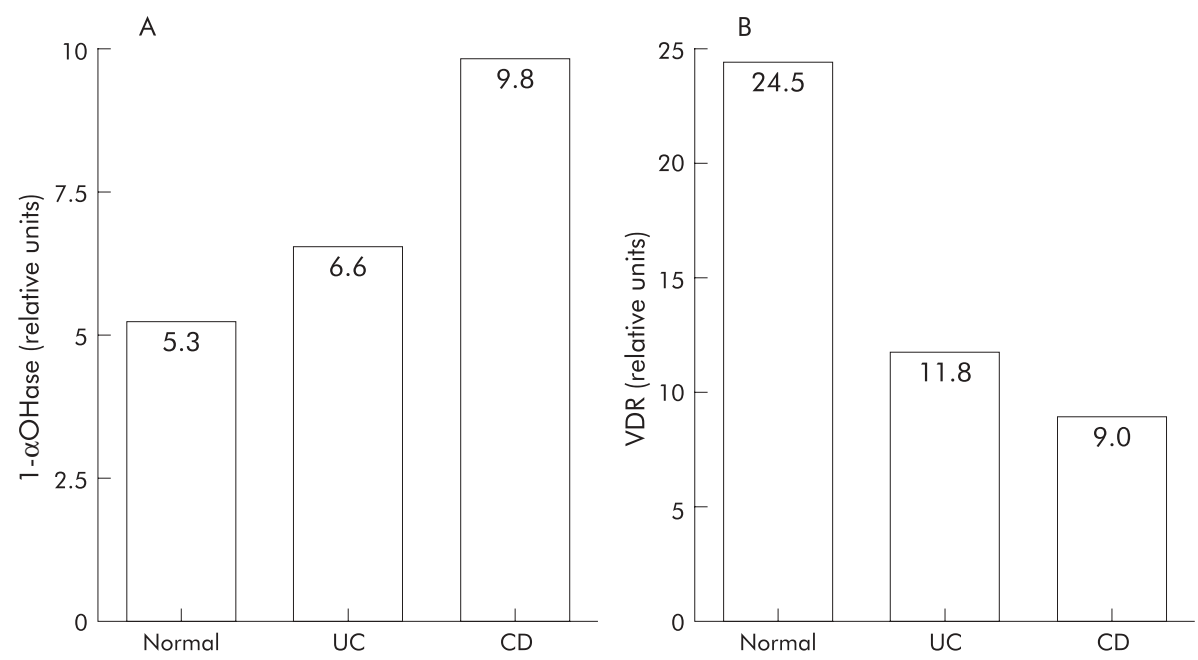

Figure 5 Expression of $1 \alpha$-hydroxylase and vitamin D receptor (VDR) in normal, Crohn's disease (CD), and ulcerative colitis (UC) colons. $1 \alpha$-Hydroxylase (A) and VDR (B) mRNA expression was assessed by quantitative real time polymerase chain reaction. These data represent an average of 10 mucosal biopsy samples each from patients with CD or UC.

suppression of Thl cytokine secretion and T cell proliferation, as we and others have described in other systems. ${ }^{4473} 74$ Indeed, in animal models of colitis limiting the substrate for $1,25(\mathrm{OH})_{2} \mathrm{D}$ or using mice with disruption of the VDR gene results in worse colitis. ${ }^{75}{ }^{76}$ Clearly, in many instances of $\mathrm{CD}$, local synthesis of $1,25(\mathrm{OH})_{2} \mathrm{D}$ may not be sufficient to suppress tissue inflammation, and in these cases unregulated $1 \alpha$-hydroxylase may lead to raised circulating levels of the hormone. As with sarcoidosis, the extent to which this occurs is likely to be dependent on the severity of the disease but also on serum levels of $25(\mathrm{OH}) \mathrm{D}$ or, in other words, vitamin D status.

The clinical implications of our work are several. Firstly, elevated $1,25(\mathrm{OH})_{2} \mathrm{D}$ may serve as a marker of $\mathrm{CD}$. The positive and negative predictive values for supranormal
$(>60 \mathrm{pg} / \mathrm{ml}) \quad 1,25(\mathrm{OH})_{2} \mathrm{D}$ in patients with $\mathrm{CD}$ are $97 \%$ and $75 \%$, respectively. These numbers are comparable with serological tests currently available for distinguishing CD from UC. ${ }^{77-79}$ Secondly, clinicians frequently recommend that patients take calcium and vitamin $\mathrm{D}$ supplementation to prevent or treat osteopenia and osteoporosis in patients with IBD. Based on our work, measuring vitamin D metabolites is important in identifying those patients with an additional risk factor for developing low BMD. Moreover, we have also found that patients with elevated $1,25(\mathrm{OH})_{2} \mathrm{D}$ frequently have hypercalciuria and may be prone to renal nephrolithiasis (data not shown). The correct intervention in these patients is not established. Strategies to reduce bone loss in these patients may include non-glucocorticoid treatment of the underlying IBD and potentially hydroxychloroquine which

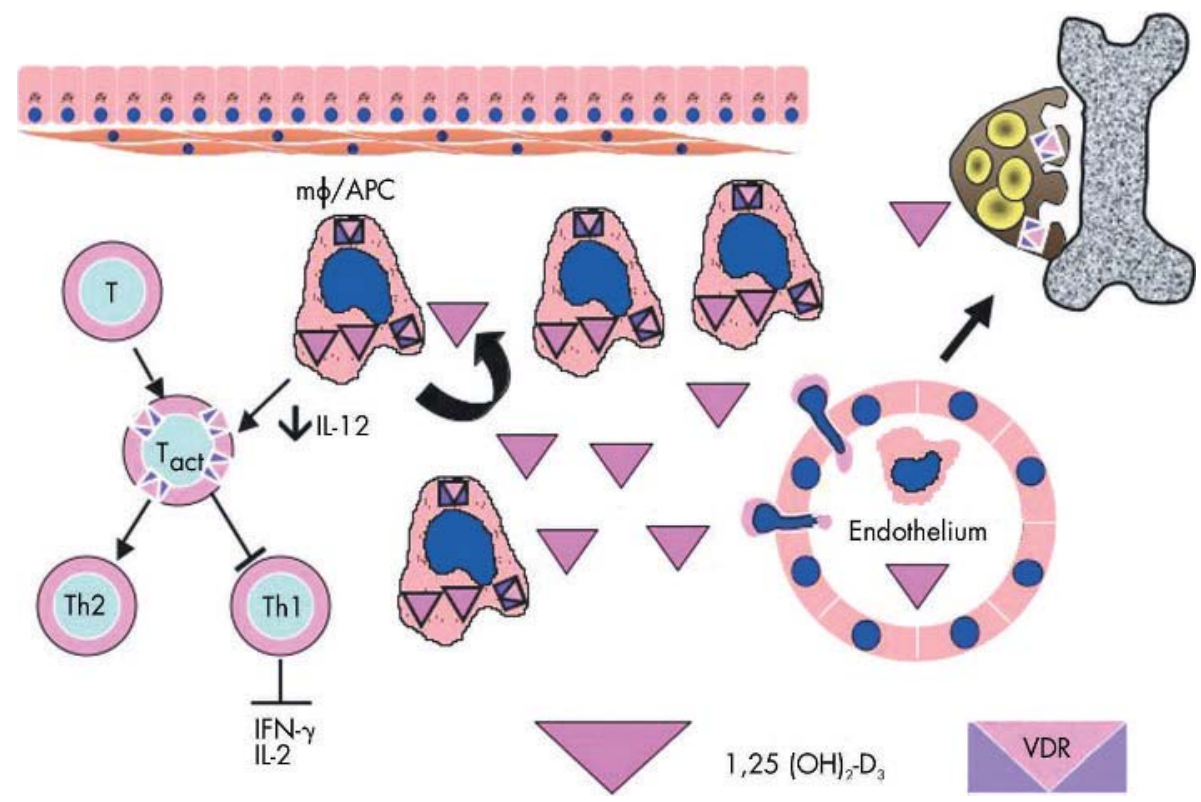

Figure 6 Model of elevated 1,25-dihydroxyvitamin $\mathrm{D}\left(1,25(\mathrm{OH})_{2} \mathrm{D}\right)$ in patients with Crohn's disease. The inflamed intestine in Crohn's disease is characterised by an infiltrate of mononuclear cells, including antigen presenting cells (APC) and macrophages (m $\Phi)$. These cells express the $1 \alpha$-hydroxylase enzyme resulting in conversion of 25 -hydroxyvitamin $D$ to $1,25(\mathrm{OH})_{2} \mathrm{D}$. T cells and APC/m $\mathrm{m}$ express vitamin $\mathrm{D}$ receptors (VDR). Thus $1,25(\mathrm{OH})_{2} \mathrm{D}$ may have both paracrine and autocrine effects to suppress Th1-type differentiation. Excess local production of $1,25(\mathrm{OH})_{2} \mathrm{D}$ may lead to spillage of the hormone into the systemic circulation and distant osteoclast activation and bone resorption. IFN- $\gamma$, interferon $\gamma ;$ IL-2, interleukin 2. 
inhibits the conversion of $25(\mathrm{OH}) \mathrm{D}$ to $1,25(\mathrm{OH})_{2} \mathrm{D}^{80}$ In sarcoidosis patients with hypercalcaemia secondary to elevated $1,25(\mathrm{OH})_{2} \mathrm{D}$, treatment with hydroxychloroquine is effective in reducing serum calcium. ${ }^{81}$ Preliminarily, we have treated several CD patients with low dose (200 mg daily) oral hydroxychloroquine and lowered serum $1,25(\mathrm{OH})_{2} \mathrm{D}$ levels and urinary calcium excretion (unpublished studies). Finally, if elevated $1,25(\mathrm{OH})_{2} \mathrm{D}$ is an indirect marker of Thl mediated inflammation, we may be able to use this test to better predict who will respond to medical therapy directed at Thl cytokines in CD. More research will need to be done to better characterise this interesting subgroup of patients.

\section{ACKNOWLEDGEMENTS}

Supported by AI40403 and General Clinical Research Center grant RR00043 from the National Institutes of Health and the Cedars-Sinai Inflammatory Bowel Disease Translational Research Fund.

\section{Authors' affiliations}

M T Abreu, E A Vasiliauskas, Division of Gastroenterology,

Inflammatory Bowel Disease Center, Steven Spielberg Pediatric Research Center, Burns and Allen Research Institute, Cedars-Sinai Medical Center, Los Angeles, CA, USA

V Kantorovich, U Gruntmanis, R Matuk, K Daigle, S Chen, J S Adams, Department of Medicine, Division of Endocrinology, Steven Spielberg Pediatric Research Center, Burns and Allen Research Institute, CedarsSinai Medical Center, Los Angeles, CA, USA

D Zehnder, M Hewison, Division of Medical Sciences, University of Birmingham, Birmingham, UK

Y-C Lin, $\mathbf{H}$ Yang, Department of Pediatrics, Division of Medical Genetics, Steven Spielberg Pediatric Research Center, Burns and Allen Research Institute, Cedars-Sinai Medical Center, Los Angeles, CA, USA

\section{REFERENCES}

1 Adachi JD, Rostom A. Metabolic bone disease in adults with inflammatory bowel disease. Inflamm Bowel Dis 1999:5:200-11.

2 Clements D, Motley RJ, Evans WD, et al. Longitudinal study of cortical bone loss in patients with inflammatory bowel disease. Scand J Gastroenterol 1992;27:1055-60.

3 Motley RJ, Clements D, Evans WD, et al. A four-year longitudinal study of bone loss in patients with inflammatory bowel disease. Bone Miner 1993;23:95-104

4 Valentine JF, Sninsky CA. Prevention and treatment of osteoporosis in patients with inflammatory bowel disease. Am J Gastroenterol 1999;94:878-83.

5 Bertolini DR, Nedwin GE, Bringman TS, et al. Stimulation of bone resorption and inhibition of bone formation in vitro by human tumour necrosis factors. Nature 1986;319:516-18

6 Lader CS, Flanagan AM. Prostaglandin E2, interleukin lalpha, and tumor necrosis factor-alpha increase human osteoclast formation and bone resorption in vitro. Endocrinology 1998;139:3157-64.

7 Dinca M, Fries W, Luisetto G, et al. Evolution of osteopenia in inflammatory bowel disease. Am J Gastroenterol 1999;94:1292-7.

8 Pollak RD, Karmeli F, Eliakim R, et al. Femoral neck osteopenia in patients with inflammatory bowel disease. Am J Gastroenterol 1998:93:1483-90.

9 Schulte C, Dignass AU, Mann K, et al. Reduced bone mineral density and unbalanced bone metabolism in patients with inflammatory bowel disease. Inflamm Bowel Dis 1998;4:268-75.

10 Weinstein RS, Jilka RL, Parfitt AM, et al. Inhibition of osteoblastogenesis and promotion of apoptosis of osteoblasts and osteocytes by glucocorticoids. Potential mechanisms of their deleterious effects on bone. J Clin Invest 1998; 102:274-82.

11 Ardizzone S, Bollani S, Bettica P, et al. Altered bone metabolism in inflammatory bowel disease: there is a difference between Crohn's disease and ulcerative colitis. J Intern Med 2000;247:63-70.

12 Schoon EJ, van Nunen AB, Wouters RS, et al. Osteopenia and osteoporosis in Crohn's disease: prevalence in a Dutch population-based cohort. Scand J Gastroenterol 2000;(suppl 232):43-7.

13 Thearle M, Horlick M, Bilezikian JP, et al. Osteoporosis: an unusual presentation of childhood Crohn's disease. J Clin Endocrinol Metab 2000;85:2122-6.

14 Bernstein CN, Seeger LL, Sayre JW, et al. Decreased bone density in inflammatory bowel disease is related to corticosteroid use and not disease diagnosis. J Bone Miner Res 1995; 10:250-6.

15 Silvennoinen JA, Karttunen TJ, Niemela SE, et al. A controlled study of bone mineral density in patients with inflammatory bowel disease. Gut 1995;37:71-6

16 Lamb EJ, Wong T, Smith DJ, et al. Metabolic bone disease is present at diagnosis in patients with inflammatory bowel disease. Aliment Pharmacol Ther 2002; 16:1895-902.

17 Vestergaard P, Krogh K, Rejnmark L, et al. Fracture risk is increased in Crohn's disease, but not in ulcerative colitis. Gut 2000;46:176-81.
18 Bernstein CN, Blanchard JF, Leslie W, et al. The incidence of fracture among patients with inflammatory bowel disease. A population-based cohort study. Ann Intern Med 2000; 133:795-9.

19 Vestergaard P, Mosekilde L. Fracture risk in patients with celiac disease, Crohn's disease, and ulcerative colitis: a nationwide follow-up study of 16,416 patients in Denmark. Am J Epidemiol 2002;156:1-10.

20 Semeao EJ, Stallings VA, Peck SN, et al. Vertebral compression fractures in pediatric patients with Crohn's disease. Gastroenterology 1997:112:1710-13.

21 Stockbrugger RW, Schoon EJ, Bollani S, et al. Discordance between the degree of osteopenia and the prevalence of spontaneous vertebral fractures in Crohn's disease. Aliment Pharmacol Ther 2002;16:1519-27.

22 Klaus J, Armbrecht G, Steinkamp M, et al. High prevalence of osteoporotic vertebral fractures in patients with Crohn's disease. Gut 2002;51:654-8.

23 Faubion WA ir, Loftus EV ir, Harmsen WS, et al. The natural history of corticosteroid therapy for inflammatory bowel disease: a population-based study. Gastroenterology 2001;121:255-60.

24 Munkholm P, Langholz E, Davidsen $M$, et al. Frequency of glucocorticoid resistance and dependency in Crohn's disease. Gut 1994;35:360-2.

25 Abitbol V, Roux C, Chaussade S, et al. Metabolic bone assessment in patients with inflammatory bowel disease. Gastroenterology 1995;108:417-22.

26 Croucher PI, Vedi S, Motley RJ, et al. Reduced bone formation in patients with osteoporosis associated with inflammatory bowel disease. Osteoporosis Int 1993;3:236-41.

27 Compston JE, Judd D, Crawley EO, et al. Osteoporosis in patients with inflammatory bowel disease. Gut 1987;28:410-15.

28 Cino M, Greenberg GR. Bone mineral density in Crohn's disease: a longitudinal study of budesonide, prednisone, and nonsteroid therapy. Am J Gastroenterol 2002;97:915-21.

29 Manolagas SC. Corticosteroids and fractures: a close encounter of the third cell kind. J Bone Miner Res 2000;15:1001-5

30 Schoon EJ, Bollani S, Mills PR, et al. Budesonide versus prednisolone: effect on bone mineral density in patients with ileocecal Crohn's disease. Am J Gastroenterol 2002;97:A827.

31 Roux C, Abitbol V, Chaussade S, et al. Bone loss in patients with inflammatory bowel disease: a prospective study. Osteoporosis Int 1995;5:156-60.

32 Compston JE, Horton LW, Laker MF, et al. Bone disease after jejuno-ileal bypass for obesity. Lancet 1978;2:1-4.

33 Compston JE, Ayers AB, Horton LW, et al. Osteomalacia after small-intestinal resection. Lancet 1978;1:9-12.

34 Hessov I, Mosekilde L, Melsen F, et al. Osteopenia with normal vitamin D metabolites after small-bowel resection for Crohn's disease. Scand J Gastroenterol 1984;19:691-6.

35 Silvennoinen JA, Lehtola JK, Niemela SE. Smoking is a risk factor for osteoporosis in women with inflammatory bowel disease. Scand J Gastroenterol 1996;31:367-71.

36 Schulte CM, Dignass AU, Goebell H, et al. Genetic factors determine extent of bone loss in inflammatory bowel disease. Gastroenterology 2000;119:909-20.

37 Compston JE, Horton LW. Oral 25-hydroxyvitain D3 in treatment of osteomalacia associated with ileal resection and cholestyramine therapy. Gastroenterology 1978;74(5 Pt 1):900-2.

38 Driscoll RH jr, Meredith SC, Sitrin M, et al. Vitamin D deficiency and bone disease in patients with Crohn's disease. Gastroenterology 1982;83:1252-8.

39 Harries AD, Brown R, Heatley RV, et al. Vitamin D status in Crohn's disease: association with nutrition and disease activity. Gut 1985;26:1197-203.

40 Vogelsang $H$, Ferenci $P$, Woloszczuk W, et al. Bone disease in vitamin Ddeficient patients with Crohn's disease. Dig Dis Sci 1989;34:1094-9.

41 Brown AJ, Dusso A, Slatopolsky E. Vitamin D. Am J Physiol 1999;277(2 Pf 2):F157-75.

42 Feldman D. Vitamin D, parathyroid hormone, and calcium: a complex regulatory network. Am J Med 1999;107:637-9.

43 Bland R, Zehnder D, Hewison M. Expression of 25-hydroxyvitamin D3lalpha-hydroxylase along the nephron: new insights into renal vitamin D metabolism. Curr Opin Nephrol Hypertens 2000;9:17-22.

44 Hewison M, Zehnder D, Bland R, et al. 1 alpha-Hydroxylase and the action of vitamin D. J Mol Endocrinol 2000;25:141-8

45 Koutkia P, Lu Z, Chen T, et al. Treatment of vitamin D deficiency due to Crohn's disease with tanning bed ultraviolet B radiation. Gastroenterology $2001 ; 121: 1485-8$.

46 Jahnsen J, Falch J, Mowinckel P, et al. Vitamin D status, parathyroid hormone and bone mineral density in patients with inflammatory bowel disease. Scand J Gastroenterol 2002;37:192-9.

47 Vogelsang $\mathrm{H}$, Ferenci $\mathrm{P}$, Resch $\mathrm{H}$, et al. Prevention of bone mineral loss in patients with Crohn's disease by long-term oral vitamin D supplementation. Eur J Gastroenterol Hepatol 1995;7:609-14

48 Bernstein CN, Seeger LL, Anton PA, et al. A randomized, placebo-controlled trial of calcium supplementation for decreased bone density in corticosteroidusing patients with inflammatory bowel disease: a pilot study. Aliment Pharmacol Ther 1996;10:777-86.

49 Bosch X. Hypercalcemia due to endogenous overproduction of 1,25 dihydroxyvitamin D in Crohn's disease. Gastroenterology 1998;1 14:1061-5.

50 Adams JS, Singer FR, Gacad MA, et al. Isolation and structural identification of 1,25-dihydroxyvitamin D3 produced by cultured alveolar macrophages in sarcoidosis. J Clin Endocrinol Metab 1985;60:960-6.

51 Conron M, Young C, Beynon HL. Calcium metabolism in sarcoidosis and its clinical implications. Rheumatology (Oxford) 2000;39:707-13.

52 Yoshida EM. The Crohn's Disease Activity Index, its derivatives and the Inflammatory Bowel Disease Questionnaire: a review of instruments to assess Crohn's disease. Can J Gastroenterol 1999;13:65-73. 
53 Anonymous. Assessment of fracture risk and its application to screening for postmenopausal osteoporosis. Report of a WHO Study Group. World Health Organ Tech Rep Ser 1994;843:1-129.

54 Adachi JD, Olszynski WP, Hanley DA, et al. Management of corticosteroidinduced osteoporosis. Semin Arthritis Rheum 2000;29:228-51.

55 Bland R, Worker CA, Noble BS, et al. Characterization of 11 betahydroxysteroid dehydrogenase activity and corticosteroid receptor expression in human osteosarcoma cell lines. J Endocrinol 1999;161:455-64.

56 Zehnder D, Bland R, Williams MC, et al. Extrarenal expression of 25hydroxyvitamin d(3)-1 alpha-hydroxylase. J Clin Endocrinol Metab 2001;86:888-94

57 Zehnder D, Bland R, Walker EA, et al. Expression of 25-hydroxyvitamin D3 lalpha-hydroxylase in the human kidney. J Am Soc Nephrol 1999:10:2465-73.

58 SAS Institute I. SAS/STAT User's Guide (Statistical Analysis Software (SAS)), version 6.12. Cary, NC: SAS Institute Inc, 1990

59 Adams JS, Sharma OP, Gacad MA, et al. Metabolism of 25-hydroxyvitamin D3 by cultured pulmonary alveolar macrophages in sarcoidosis. J Clin Invest 1983:72:1856-60.

60 Adams JS, Gacad MA. Characterization of 1 alpha-hydroxylation of vitamin D3 sterols by cultured alveolar macrophages from patients with sarcoidosis. J Exp Med 1985;161:755-65.

61 Loftus EV ir, Crowson CS, Sandborn WJ, et al. Long-term fracture risk in patients with Crohn's disease: a population-based study in Olmsted County, Minnesota. Gastroenterology 2002;123:468-75

62 Haderslav KV, Tjellesen H, Sorensen HA, et al. Alendronate increases lumbar spine bone mineral density in patients with Crohn's disease. Gastroenterology 2000; 119:639-46.

63 Bailen LS. Bones and Crohn's: should we treat Crohn's disease patients with alendronate? Inflamm Bowel Dis 2001;7:175-6.

64 Scharla SH, Minne HW, Lempert UG, et al. Bone mineral density and calcium regulating hormones in patients with inflammatory bowel disease (Crohn's disease and ulcerative colitis). Exp Clin Endocrinol 1994;102:44-9.

65 Leichtmann GA, Bengoa JM, Bolt MJ, et al. Intestinal absorption of cholecalciferol and 25-hydroxycholecalciferol in patients with both Crohn's disease and intestinal resection. Am J Clin Nutr 1991;54:548-52.

66 Deluca HF, Cantorna MT. Vitamin D: its role and uses in immunology. FASEB J 2001;15:2579-85.

67 Van Etten E, Decallonne B, Verlinden L, et al. Analogs of 1alpha,25dihydroxyvitamin D3 as pluripotent immunomodulators. J Cell Biochem 2003;88:223-6.
68 van Halteren AG van Etten E, de Jong EC, et al. Redirection of human autoreactive T-cells Upon interaction with dendritic cells modulated by TX527, an analog of 1,25 dihydroxyvitamin D(3). Diabetes 2002;51:2119-25

69 Hewison M, Freeman L, Hughes SV, et al. Differential regulation of vitamin D receptor and its ligand in human monocyte-derived dendritic cells. J Immunol 2003;170:5382-90.

70 Hewison M, Zehnder D, Chakraverty R, et al. Vitamin D and barrier function: a novel role for extra-renal lalpha-hydroxylase. Mol Cell Endocrinol 2004;215:31-8.

71 Chambers TJ, Morson BC. The granuloma in Crohn's disease. Gut 1979;20:269-74

72 Heimann TM, Miller F, Martinelli G, et al. Correlation of presence of granulomas with clinical and immunologic variables in Crohn's disease. Arch Surg 1988; 123:46-8.

73 Zehnder D, Hewison M. The renal function of 25-hydroxyvitamin D3-1 alphahydroxylase. Mol Cell Endocrinol 1999;151:213-20.

74 Hewison M, Gacad MA, Lemire J, et al. Vitamin D as a cytokine and hematopoetic factor. Rev Endocrine Metab Dis 2001 ;2:217-27.

75 Cantorna MT, Munsick C, Bemiss C, et al. 1,25-Dihydroxycholecalciferol prevents and ameliorates symptoms of experimental murine inflammatory bowel disease. J Nutr 2000;130:2648-52.

76 Froicu M, Weaver V, Wynn T, et al. A crucial role for the vitamin D receptor in experimental inflammatory bowel diseases. Mol Endocrinol 2003; 17:2386-92.

77 Quinton JF, Sendid B, Reumaux D, et al. Anti-Saccharomyces cerevisiae mannan antibodies combined with antineutrophil cytoplasmic autoantibodies in inflammatory bowel disease: prevalence and diagnostic role. Gut 1998:42:788-91.

78 Peeters $M$, Joossens S, Vermeire $S$, et al. Diagnostic value of antiSaccharomyces cerevisiae and antineutrophil cytoplasmic autoantibodies in inflammatory bowel disease. Am J Gastroenterol 2001;96:730-4.

79 Vermeire S, Joossens S, Peeters M, et al. Comparative study of ASCA (antiSaccharomyces cerevisiae antibody) assays in inflammatory bowel disease. Gastroenterology 2001;120:827-33

80 Barre PE, Gascon-Barre M, Meakins JL, et al. Hydroxychloroquine treatment of hypercalcemia in a patient with sarcoidosis undergoing hemodialysis. Am J Med 1987;82:1259-62.

81 Adams JS, Diz MM, Sharma OP. Effective reduction in the serum 1,25dihydroxyvitamin $\mathrm{D}$ and calcium concentration in sarcoidosis-associated hypercalcemia with short-course chloroquine therapy. Ann Intern Med 1989;111:437-8. 